\title{
New Propagation Model Optimization Approach based on Particles Swarm Optimization Algorithm
}

\author{
Deussom Djomadji Eric Michel \\ Department of Electrical and Telecommunications \\ Engineering; National Advanced School of \\ Engineering of Yaoundé; University of Yaoundé I, \\ CAMEROON
}

\begin{abstract}
Propagation models are keys components of coverage planning. With the deployment of $4 \mathrm{G}$ network worldwide, operators need to plan the coverage of their network efficiently, in order to minimize cost and improve the quality of service.

In this paper, the standard model $\mathrm{K}$ factors is taken into account to develop a method for tuning propagation models based on particle swarm optimization algorithm. The data are collected on the existing CDMA2000 1X-EVDO rev B network in the town of Yaoundé, capital of Cameroon. The root mean squared error (RMSE) between actual measurements and radio data obtained from the prediction model developed is used to test and validate the technique. The values of the RMSE obtained by the new model and those obtained by the standard model of OKUMURA HATA in urban area are also compared. Through the comparison of RMSE from optimized model and OKUMURA HATA, it can be concluded that the new model developed using particle swarm optimization performs better than the OKUMURA HATA model and is more accurate. The new model is also more representative of the local environment and also similar to the optimized model obtained when using linear regression method. This method can be applied anywhere to optimize existing propagation model.
\end{abstract}

\section{General Terms}

Propagation model optimization

\section{Keywords}

Particles swarm optimization algorithm, Radio propagation, mobile network, propagation model optimization.

\section{INTRODUCTION}

A propagation model suitable for a given environment is an essential element in the planning and optimization of a mobile network. With the increasing demand of high speed data services, particular emphasis must be made on the size of the radio network. Propagation models are widely used in network planning, especially for expansions or new deployment projects such as LTE services. To determine the characteristics of a radio propagation channel, tests of the real propagation models and calibration of the existing models are required to obtain a propagation model that accurately reflects the characteristics of radio propagation in the given environment.

The proposed propagation model optimization approach here is based on particles swarm optimization (PSO) algorithm, it enables to optimize more than 2 parameters (up to 6 parameters) in a propagation model formula compared to linear regression mostly used by authors worldwide which is limited on the optimization of only 2 parameters. In addition PSO can output not only one solution, but a set of possible

\author{
Tonye Emmanuel \\ Department of Electrical and Telecommunications \\ Engineering; National Advanced School of \\ Engineering of Yaoundé; University of Yaoundé I, \\ CAMEROON
}

solutions, among them the best one is selected as final one. Furthermore the solution has more diversity compare to that of linear regression method. This article will be articulated as follows: in section 2, the background of the work is presented, followed in section 3 by the experimental details. Next a description of the methodology adopted is presented in section 4. The results of the implementation of the algorithm, the validation of the results and comments will be provided in section 5 and finally we have a conclusion in section 6 .

\section{BACKGROUND}

There are several software used for network planning that includes calibration of models such as ASSET, PLANET, and ATTOL.

Several authors have developed new approaches for the determination of propagation models or have studied the calibration of propagation models. Deussom and Tonye [1] worked on "New Approach for Determination of Propagation Models Adapted To an Environment Based On Genetic Algorithms: Application to the City Of Yaoundé, Cameroon"; R. Mardeni and K. F. Kwan [2] presented "Optimization of Hata prediction model in suburban area in Malaysia"; Chhaya Dalela, and al [3] who worked on "tuning of Cost231 Hata model for radio wave propagation prediction"; Medeisis and Kajackas [4] presented "the tuned Okumura Hata model in urban and rural areas at Lituania at 160, 450, 900 and 1800 MHz bands; Deussom E. and Tonye E. [5] worked on " Optimization of Okumura Hata Model in $800 \mathrm{MHz}$ based on Newton Second Order algorithm. Case of Yaoundé, Cameroon", MingjingYang et al. [6] in China have presented "A Linear Least Square Method of Propagation Model Tuning for 3G Radio Network Planning", Chen, Y.H. and Hsieh, K.L [7] Taiwan presented "has Dual Least - Square Approach of Tuning Optimal Propagation Model for existing 3G Radio Network", Allam Mousa, Yousef Dama et Al [8] in Palestine presented "Optimizing Outdoor Propagation Model based on Measurements for Multiple RF Cell”.

\subsection{State of art on propagation model optimization based on linear regression.}

2.1.1 K factors propagation model [9]

There are many propagation models presented in scientific literature, but this modeling is based on $\mathrm{K}$ factor propagation model.

The General form of the $\mathrm{K}$ factors model is given by the following equation:

$L_{p}=K_{1}+K_{2} \log (\mathrm{d})+K_{3} * h_{m}+K_{4} * \log \left(h_{m}\right)+K_{5} *$

$\log \left(h_{b}\right)+K_{6} * \log \left(h_{b}\right) \log (d)+K_{7 d i f f n}+K_{\text {clutter }}$

$\mathrm{K}_{1}$ constant related to the frequency, $\mathrm{K}_{2}$ constant of attenuation of the distance or propagation exponent, $\mathrm{K}_{3}$ and $\mathrm{K}_{4}$ are correction factors of mobile station height; $\mathrm{K}_{5}$ and $\mathrm{K}_{6}$ 
are correction factors of BTS height, $\mathrm{K}_{7}$ is the diffraction factor, and $\mathrm{K}_{\text {clutter }}$ correction factor due to clutter type.

The $\mathrm{K}$ parameter values vary according to the type of the landscape and the characteristics of the propagation of the city environment; the following table gives values of $\mathrm{K}$ for a medium-sized town.

Eq. (1) could also be written in the following form:

$\mathbf{L}_{\mathbf{p}}=\left(\mathbf{K}_{\mathbf{1}}+\mathbf{K}_{\mathbf{7 d i f f n}}+\mathbf{K}_{\text {clutter }}\right)+\mathbf{K}_{\mathbf{2}} \log (\mathbf{d})+\mathbf{K}_{\mathbf{3}} * \mathbf{h}_{\mathbf{m}}+$ $\mathbf{K}_{\mathbf{4}} * \log \left(\mathbf{h}_{\mathbf{m}}\right)+\mathbf{K}_{\mathbf{5}} * \log \left(\mathbf{h}_{\mathbf{b}}\right)+\mathbf{K}_{\mathbf{6}} \log \left(\mathbf{h}_{\mathbf{b}}\right) \log (\mathbf{d})$

Assuming $K_{1}^{\prime}=\left(K_{1}+K_{7 \text { diffn }}+K_{\text {clutter }}\right)$, Eq. (1) gets the form below:

$\mathbf{L}_{\mathrm{p}}=\mathbf{K}_{1}+\mathbf{K}_{2} \log (d)+K_{3} * \mathbf{h}_{\mathbf{m}}+\mathbf{K}_{\mathbf{4}} * \log \left(\mathbf{h}_{\mathrm{m}}\right)+\mathbf{K}_{5} *$

$\log \left(h_{b}\right)+K_{6} \log \left(h_{b}\right) \log (d)$

\subsubsection{Propagation model optimization based on} linear regression

Eq. (2) can be rearranged as:

$L_{p}=\left[K_{1}+K_{3} * h_{m}+K_{4} * \log \left(h_{m}\right)+K_{5} * \log \left(h_{b}\right)\right]+$

$\left[\log \left(h_{b}\right)+K_{2}\right] \log (d)$

Assuming $A=K_{1}+K_{3} * h_{m}+K_{4} * \log \left(h_{m}\right)+K_{5} * \log \left(h_{b}\right)$ and $B=K_{6} \log \left(h_{b}\right)+K_{2}$

Eq. (3) becomes $\quad \mathbf{L}_{\mathbf{p}}=\mathbf{A}+\mathbf{B} \log (\mathbf{d})$

Eq. (4) can also be rewrite in vector form as:

$\mathbf{L}_{\mathbf{p}}=\left[\begin{array}{ll}\mathbf{1} & \log (\mathbf{d})\end{array}\right] *\left[\begin{array}{l}\mathbf{A} \\ \mathbf{B}\end{array}\right]$

Once getting the measured propagation loss $\mathrm{L}_{\mathrm{i}}$ for $\mathrm{N}$ points at different distances $d_{i}$, Eq. (5), can be written in matrix form as

$\left[\begin{array}{c}L_{1} \\ L_{2} \\ \vdots \\ L_{N}\end{array}\right]=\left[\begin{array}{cc}1 & \log \left(d_{1}\right) \\ 1 & \log \left(d_{i}\right) \\ & \vdots \\ 1 & \log \left(d_{N}\right)\end{array}\right] *\left[\begin{array}{l}A \\ B\end{array}\right]$

Eq. (6) can be re arranged in a compact form as:

$L=M_{0} * T$

With $\mathrm{M}$ and $\mathrm{K}$ defined as below. And $X^{T}$ is the transposed vector of $X$.

$M_{0}=\left[\begin{array}{cc}1 & \log \left(d d_{1}\right) \\ 1 & \log \left(d_{i}\right) \\ & \vdots \\ 1 & \log \left(d_{N}\right)\end{array}\right] \quad$ and $\quad T=\left[\begin{array}{l}A \\ B\end{array}\right]$

The optimization process consists of minimizing the Euclidian distance between the measured propagation loss $\mathrm{L}_{\mathrm{M}}$ and the prediction $\boldsymbol{L}=\boldsymbol{M}_{\mathbf{0}} * \boldsymbol{T}$. Let $E=\frac{1}{N}\left\|L_{M}-M_{\mathbf{0}} * T\right\|^{2}$ be the mean squared error, $\mathrm{E}$ is minimal if its gradient relatively to $\mathrm{T}$ is null, that is $\frac{\partial E}{\partial T}=0$, and then

$$
\begin{aligned}
\frac{\partial E}{\partial T}=0 & =>\Delta E=\frac{1}{N}\left(2 M_{0}{ }^{T} M_{0} T-2 M_{0}{ }^{T} L_{M}\right) \\
& =>\frac{1}{N}\left(2 M_{0}{ }^{T} M_{0} T-2 M_{0}{ }^{T} L_{M}\right)=0 .
\end{aligned}
$$

Finally the solution is:

$$
T^{*}=\left(M_{0}{ }^{T} M_{0}\right)^{-1} M_{0}{ }^{T} L_{M}=\left[\begin{array}{l}
A^{*} \\
B^{*}
\end{array}\right]
$$

Therefore for $\mathrm{K}_{3}, \mathrm{~K}_{4}, \mathrm{~K}_{5}$ and $\mathrm{K}_{6}$ constants, we get:

$K_{1}=A^{*}-\left(K_{3} * h_{m}+K_{4} * \log \left(h_{m}\right)+K_{5} * \log \left(h_{b}\right)\right)$
$K_{2}=B^{*}-K_{6} * \log \left(h_{b}\right)$

Finally it is clear that the propagation model tuning based on linear regression can optimize only 2 parameters, the remaining are supposed constant. Our main contribution on this paper is to define a new approach that could optimize not only 2 parameters but all. To achieve this, in this study, the data were collected through drive test on CDMA1X EVDO RevB network in the city of Yaoundé, capital of Cameroon.

\section{EXPERIMENT}

\subsection{Propagation environment}

In this study, the data is collected from 4 BTS distributed throughout the city of Yaoundé on a CDMA1X EVDO RevB network. The BTS represent Yaoundé downtown and the transition from downtown to the suburb areas. For each category, similar environments are used, and results compared. The table below presents the categories according to the position of the BTS.

Table 1: Types of environment

\begin{tabular}{|c|c|c|}
\hline Categories & A & B \\
\hline $\begin{array}{c}\text { Urban } \\
\text { characteristics }\end{array}$ & Dense urban & Urban \\
\hline Concerned BTS & $\begin{array}{c}\text { Ministere PTT (A1) } \\
\text { Bastos (A2) }\end{array}$ & $\begin{array}{c}\text { Hotel du plateau(B1) } \\
\text { Biyem Assi(B2) }\end{array}$ \\
\hline
\end{tabular}

\subsection{Equipments description}

3.2.1 Simplified description of BTS used. [10]

BTS involved in our data collection process are HUAWEI Technologies manufactured. The following table shows the specifications of the BTS

Table 2: BTS characteristics

\begin{tabular}{|l|l|l|}
\hline & BTS3606 & DBS3900 \\
\hline BTS types & Indoor BTS & $\begin{array}{l}\text { Distributed BTS } \\
\text { (Outdoor) }\end{array}$ \\
\hline Number of sectors & 3 & 3 \\
\hline Frequency Band & $\begin{array}{l}\text { Band Class 0 (800 } \\
\text { MHz) }\end{array}$ & $\begin{array}{l}\text { Band Class 0 (800 } \\
\text { MHz) }\end{array}$ \\
\hline $\begin{array}{l}\text { Downlink } \\
\text { frequency }\end{array}$ & $869 \mathrm{MHz}-894 \mathrm{MHz}$ & $869 \mathrm{MHz}-894 \mathrm{MHz}$ \\
\hline Uplink frequency & $824 \mathrm{MHz}-849 \mathrm{MHz}$ & $824 \mathrm{MHz}-849 \mathrm{MHz}$ \\
\hline $\begin{array}{l}\text { Max power (mono } \\
\text { carrier) }\end{array}$ & $20 \mathrm{~W}$ & $20 \mathrm{~W}$ \\
\hline $\begin{array}{l}\text { BTS Total power } \\
\text { (dBm) }\end{array}$ & $43 \mathrm{dBm}$ & $43 \mathrm{dBm}$ \\
\hline
\end{tabular}

The BTS engineering parameters are presented in the tables below.

Table 3: BTS engineering parameters (1)

\begin{tabular}{|c|c|c|c|c|}
\hline $\begin{array}{c}\text { BTS } \\
\text { Type }\end{array}$ & BTS name & $\begin{array}{c}\text { Latitude } \\
\text { (degree) }\end{array}$ & $\begin{array}{c}\text { Longitude } \\
\text { (degree) }\end{array}$ & $\begin{array}{c}\text { BTS } \\
\text { Altitude (m) }\end{array}$ \\
\hline 3606 & MinistryPTT & 3.86587 & 11.5125 & 749 \\
\hline 3900 & Hotel du plateau & 3.87946 & 11.5503 & 773 \\
\hline 3606 & Biyem-Assi & 3.83441 & 11.4854 & 721 \\
\hline 3900 & Camtel Bastos & 3.89719 & 11.50854 & 770 \\
\hline
\end{tabular}


Table 4: BTS engineering parameters (2)

\begin{tabular}{|c|c|c|c|c|c|}
\hline BTS name & $\begin{array}{c}\text { Antenn } \\
\text { a height }\end{array}$ & $\begin{array}{c}\text { Mean } \\
\text { elevation }\end{array}$ & $\begin{array}{c}\text { Antenna } \\
\text { effective } \\
\text { height }\end{array}$ & $\begin{array}{c}\text { Antenn } \\
\text { a's } \\
\text { Gain } \\
\text { dBi) }\end{array}$ & $\begin{array}{c}\mathbf{7 / 8} \\
\text { Feeder } \\
\text { Cable( } \\
\text { m) }\end{array}$ \\
\hline $\begin{array}{c}\text { MinistryPT } \\
\text { T }\end{array}$ & 40 & 741.82 & 47.18 & 15.5 & 45 \\
\hline $\begin{array}{c}\text { Hotel du } \\
\text { plateau }\end{array}$ & 27 & 753.96 & 46.04 & 17 & 0 \\
\hline $\begin{array}{c}\text { Biyem-Assi } \\
\text { Camtel } \\
\text { Bastos }\end{array}$ & 28 & 709.54 & 51.46 & 15.5 & 45 \\
\hline
\end{tabular}

Fig. 1 and Fig. 2 are samples of drive test done in the area A1 and $\mathrm{A} 2$

The drive test tools used for data collection are: pilot pionner software from Dinglicom, a laptop, a DC/AC converter to supply power to the laptop, a LG CDMA terminal, a dongle and a GPS receiver all install inside a Car. Fig. 3 is the collection tool install in a car.

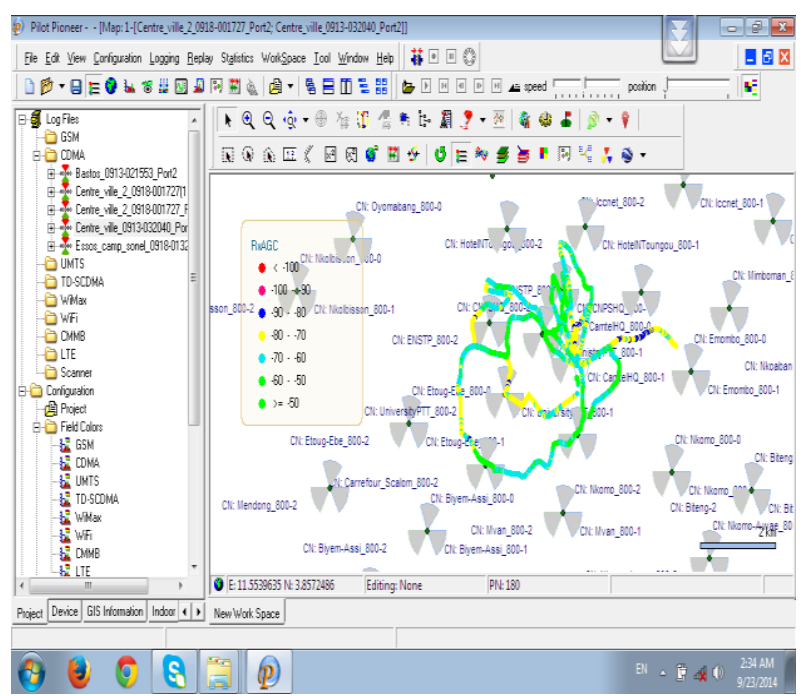

Fig. 1: Drive test in centre town (A1)

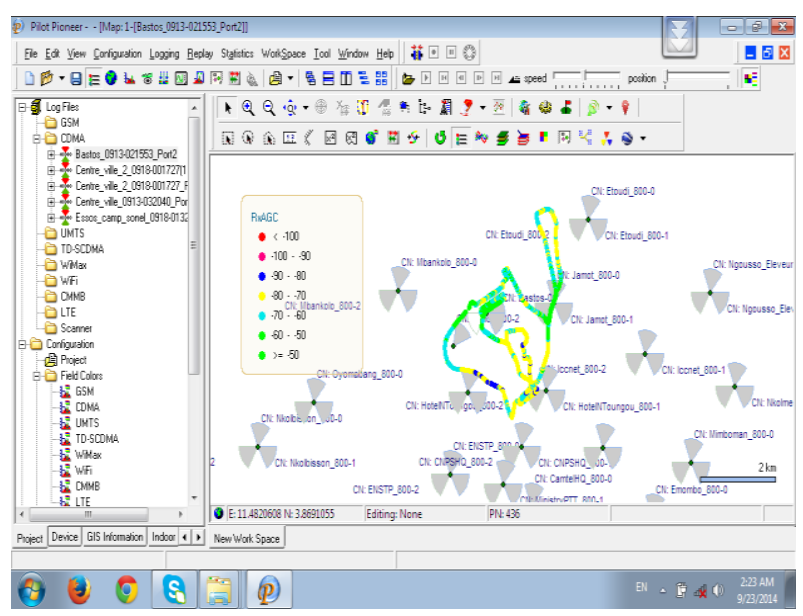

Fig. 2: Drive test in Bastos area (A2)

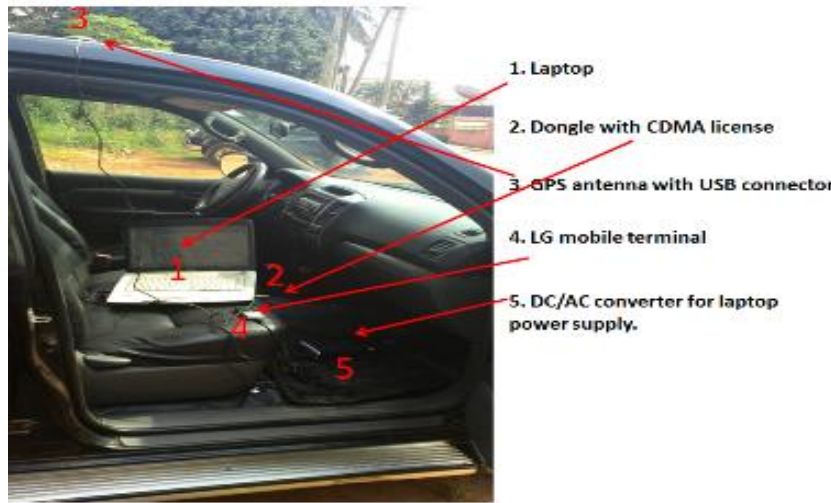

Fig. 3: Drive test Tool installed inside a car

\section{METHODS}

There are many propagation models presented in scientific literature, but our modeling is based on the $\mathrm{K}$ factor propagation model, in fact almost every propagation model can be written in the form of $\mathrm{K}$ factors propagation model in a specific frequency. First let remind Okumura Hata model.

Okumura Hata model for urban area and frequency greater than $300 \mathrm{MHz}$ is given by the following formula:

$L_{\mathrm{dB}}=\boldsymbol{A}+\boldsymbol{B} \log (\boldsymbol{d})-\boldsymbol{E}$,

With $A=69.55+26.16 \log \left(f_{c}\right)-13.82 \log \left(h_{b}\right)$

$$
B=44.9-13.82 \log \left(h_{b}\right) \text {, }
$$

$E=3.2\left(\log \left(11.75 h_{m}\right)\right)^{2}-4.97$, in fact for $h_{m}=1.5 m$, $E=9.19 * 10^{-4} \approx 0$

Then Eq. (11) can be simplified as

$L_{\mathrm{dB}}=69.55+26.16 \log \left(f_{c}\right)-13.82 \log \left(h_{b}\right)+$ $\left(44.9-13.82 \log \left(h_{b}\right)\right) \log (d)$

\subsection{Flowchart}

Fig.4 is the flowchart that represents the determination of the propagation model using PSO algorithms. Data filtering is made according to the criteria for distance and signal strength received (see table 5)

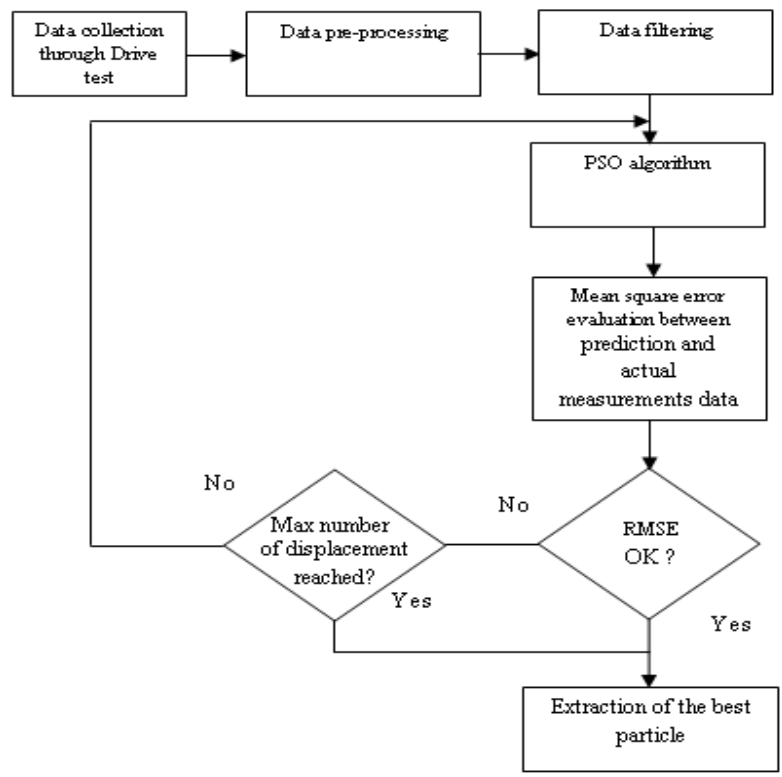

Fig. 3: PSO algorithm implementation flowchart 
Table 5. Filtering criteria. [11]

\begin{tabular}{|l|r|}
\hline Minimum distance $(\mathrm{m})$ & 100 \\
\hline Maximum distance $(\mathrm{m})$ & 10000 \\
\hline Minimum received power $(\mathrm{dBm})$ & -110 \\
\hline Maximum received power $(\mathrm{dBm})$ & -40 \\
\hline
\end{tabular}

\subsection{Particle swarm optimization algorithm.}

\section{[12]}

A PSO algorithm finds a solution by searching an extremum (maximum or minimum) on a set of possible solutions, the solution set is called a search space. The algorithm is built using the procedure described below:

- The coding of the elements of the swarm (particles),

- The generation of the initial swarm particles and position,

- Evaluation of each particle's fitness in the swarm,

- $\quad$ Particles velocity and position evaluation and update,

- Criteria to stop the algorithm based not RMSE threshold or maximum of displacements.

4.2.1 Modeling of our problem by PSO algorithm. We are trying to find a propagation model to suit any environment. Based on K factors model, Eq. (2) above can be written in matrix form as follows:

$L=\left[\begin{array}{llllll}K_{1} & K_{2} & K_{3} K_{4} & K_{5} & K_{6}\end{array}\right] *\left[\begin{array}{c}1 \\ \log (d) \\ H_{m} \\ \log \left(H_{m}\right) \\ \log \left(H_{e f f}\right) \\ \log \left(H_{\text {eff }}\right) * \log (d)\end{array}\right]$

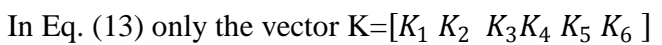

is variable depending on the values of, i $\boldsymbol{\epsilon}\{\mathbf{1}, \mathbf{2}, \mathbf{3}, \mathbf{4}, \mathbf{5}, \mathbf{6}\}$ and $\mathrm{j}$ an integer. Let:

$M=\left[\begin{array}{c}1 \\ \log (d) \\ H_{m} \\ \log \left(H_{m}\right) \\ \log \left(H_{e f f}\right) \\ \log \left(H_{\text {eff }}\right) * \log (d)\end{array}\right]$

Therefore $\mathrm{L}$ can be written in the form

$$
\boldsymbol{L}=\boldsymbol{K} * \boldsymbol{M}
$$

With $\mathrm{M}$ a constant vector for a given distance $\mathrm{d}$ and depending on whether we were under a base station of effective height $H_{\text {eff }}$.

If in the contrary the distance $\mathrm{d}$ varies for different measurement points, vector $\mathrm{M}$ becomes a $M_{i}$ vector for various measures at different distances points $d_{i}$.

The determination of the vector $\mathrm{K}$ leads to the knowledge of our propagation model L. Our searching area is therefore that containing all the possible values of the vectors of the form presented as $\mathrm{K}$ above in Eq. (14). So our particles will be $\mathrm{K}$ vectors as presented above.
It is therefore necessary for us to model all elements forming the PSO algorithm namely: the swarm, the fitness of any particles, the velocity and the position update procedure.

\subsubsection{PSO algorithm parameters}

Subsequently the following parameters are considered:

- Nit, the number of displacements,

- Nc, the number of particles of the swarm at any generation,

- $\quad \mathrm{c} 1$ and $\mathrm{c} 2$ learning factors or acceleration coefficients

- $\quad \rho 1=\mathrm{r} 1 *_{\mathrm{c} 1}$ and $\rho 2=\mathrm{r} 2 *_{\mathrm{c} 2}$ confidence coefficient.

Where $\mathrm{r} 1$ and $\mathrm{r} 2$ are two random numbers between $[0,1]$

Most authors suggested $\mathrm{r} 1=\mathrm{r} 2=2$ [13].

The coefficient of constriction $\kappa$ was introduced by Maurice clerc in [14] which helps to tighten the hyperspace of research to avoid particles moving too quickly in the search space and possibly passing next to the optimum.

$\boldsymbol{\kappa}$ is defined by the following equation :

$\kappa=1-\frac{1}{\rho}+\frac{1}{2} \sqrt{\left|\rho^{2}-4 \rho\right|} \quad[14]$

With $\rho=\rho_{1}+\rho_{2}$

The velocity is also defined by

$V i(t+1)=\kappa\left(V_{i}(t)+\rho_{1}\left(X_{\text {pbesti }}-X_{i}\right)+\rho_{2}\left(X_{\text {vbesti }}-\right.\right.$

$\left.X_{i}\right)$

And finally the new position can be deducted from former by the relation:

$X_{i}=X_{i}+V_{i}$

\subsubsection{Generation of starting swarm F}

The key point for the implementation of PSO algorithm is the coding of every particle and the generation of the initial swarm, for this work a particle will be a vector on the form of Eq. (14). Now let see how to generate the initial swarm.

The starting swarm that is generated is made up of different particles $K^{j}$ randomly generated, meeting certain criteria of integrity on the values of the different $K_{i}^{j}$ for $\mathrm{i}=1: 6$. Let $\mathrm{F}$ be the swarm.

Then $F=\left[K_{1}^{j} K_{2}^{j} K_{3}^{j} K_{4}^{j} K_{5}^{j} K_{6}^{j}\right]_{j=1: N c}$. Okumura Hata model, $\mathrm{K}$ factors model and free space propagation model put on form Eq. (14) above will give the values in the following table:

Table 6: Existing Propagation models into the form of vector $\mathbf{K}$.

\begin{tabular}{|l|c|c|c|c|c|c|}
\hline $\begin{array}{l}\text { Propagation } \\
\text { model }\end{array}$ & K1 & K2 & K3 & K4 & K5 & K6 \\
\hline $\begin{array}{l}\text { Okumura } \\
\text { Hata }\end{array}$ & 146.56 & 44.9 & 0 & 0 & -13.82 & -6.55 \\
\hline Free space & 91.28 & 20 & 0 & 0 & 0 & 0 \\
\hline K factors & 149 & 44.9 & -2.49 & 0 & -13.82 & -655 \\
\hline
\end{tabular}

The first 3 particles of our initial swarm position will be the particles corresponding to Okumura Hata model, K factors 
and free space above. The other particles need to be generated in order to complete the size of the swarm to $\mathrm{Nc}$ particles.

But before doing that, the criteria that every parameter $K_{1} K_{2} K_{3} K_{4} K_{5} K_{6}$ should respect need to be defined in other to have a solution that feat a real propagation model.

We have the following criteria for generation of the different parameters.

a) Generation of $\mathrm{K}_{4}^{\mathrm{j}}$

The parameters $\mathrm{K}_{4}^{\mathrm{j}}$ is a micro adjustment parameter with value between 0 and 1 , then: $0 \leq \mathrm{K}_{4}^{\mathrm{j}} \leq 1$. We have the following algorithm:

$$
\begin{array}{r}
\text { For } \mathrm{j}=4 \text { :Nc do } \\
\mathrm{K}_{4}^{\mathrm{j}}=\text { rand (1) }
\end{array}
$$

End for

b) Generation of $K_{1}^{\mathrm{j}}$

The parameter $K_{1}^{j}$ is searched between the values of the $K_{1}$ of free space and OKUMURA-HATA models. Let $\mathrm{K}_{1 \mathrm{el}}$ and $\mathrm{K}_{1 \mathrm{ok}}$ respectively the parameters $\mathrm{K} 1$ for of free space and OKUMURA-HATA model, then we will have: $\mathrm{K}_{1 \mathrm{el}} \leq \mathrm{K}_{1}^{\mathrm{j}} \leq$ $\mathrm{K}_{1 \mathrm{ok}}$. A random values between $\mathrm{K}_{1 \mathrm{el}}$ and $\mathrm{K}_{1 \mathrm{ok}}$ will be generated.

All this allows us to have the following algorithm:

$$
\begin{aligned}
& \text { For } \mathrm{j}=4 \text { : Nc do } \\
& \qquad \mathrm{K}_{1}^{\mathrm{j}}=\mathrm{K}_{1 \mathrm{el}}+\left(\mathrm{K}_{1 \mathrm{ok}}-\mathrm{K}_{1 \mathrm{el}}\right) * \operatorname{rand}(1)
\end{aligned}
$$

End for

c) Generation of $\mathrm{K}_{6}^{\mathrm{j}}$

This parameter will be searched between the values -6.55 and 0 , what justifies this choice is that this setting is worth these respective values for Okumura Hata and free space loss models. We will therefore have the algorithm below:

$$
\begin{aligned}
\text { For } \mathrm{j}=4 & : \mathrm{Nc} \text { do } \\
& \mathrm{K}_{6}^{\mathrm{j}}=-6.55^{*} \text { rand }(1)
\end{aligned}
$$

End for

d) Generation of parameter $K_{2}^{\mathrm{j}}$

The global adjustment parameter $\mathrm{K} 2$ should follow the criteria below:

$\mathrm{K}_{2 \mathrm{el}} \leq \mathrm{K}_{2}^{\mathrm{j}}+\mathrm{K}_{6}^{\mathrm{j}} \log \left(\mathrm{H}_{\mathrm{b}}\right) \leq \mathrm{K}_{2 \mathrm{ok}}$, in fact $\mathrm{K}_{2}^{\mathrm{j}}+\mathrm{K}_{6}^{\mathrm{j}} \log \left(\mathrm{H}_{\mathrm{b}}\right)$ is the distance attenuation factor and for that should be comprise between $\mathrm{K}_{2 \mathrm{el}}$ and $\mathrm{K}_{2 \mathrm{ok}} \cdot \mathrm{K}_{2 \mathrm{el}}=20$, and $\mathrm{K}_{2 \mathrm{ok}}=44.9-$ $6.55 \log \left(\mathrm{H}_{\mathrm{b}}\right)$, now in urban areas, the minimum possible height for a base station is 20 meters, this minimum value of $\mathrm{Hb}$, allows us to obtain the maximum value of $\mathrm{K}_{2 \mathrm{ok}}=36.8$. This allows us to write that:

$$
20-\mathrm{K}_{6}^{\mathrm{j}} \log \left(\mathrm{H}_{\mathrm{b}}\right) \leq \mathrm{K}_{2}^{\mathrm{j}} \leq 36.8-\mathrm{K}_{6}^{\mathrm{j}} \log \left(\mathrm{H}_{\mathrm{b}}\right)
$$

The following algorithm can be deduced:

$$
\begin{aligned}
& \text { For } \mathrm{j}=4: \mathrm{Nc} \text { do } \\
& \qquad \mathrm{K}_{2}^{\mathrm{j}}=20-\mathrm{K}_{6}^{\mathrm{j}} \log \left(\mathrm{H}_{\mathrm{b}}\right)+(36.8-20) * \\
& \operatorname{rand}(1)
\end{aligned}
$$

End for e) Generation of $\mathrm{K}_{5}^{\mathrm{j}}$

This parameter is negative and is in between -13.82 and 0 . (13.82 is the parameter value for $\mathrm{K}$ factor and Okumura Hata model), the algorithm below can be deduced:

$$
\begin{aligned}
& \text { For } \mathrm{j}=4: \mathrm{Nc} \text { do } \\
& \qquad \mathrm{K}_{5}^{\mathrm{j}}=-13.82+13.82 \text { *rand (1) }
\end{aligned}
$$

End for

f) Generation of $\mathrm{K}_{3}^{\mathrm{j}}$

Finally the parameter $\mathrm{K}_{3}^{\mathrm{j}}$ will vary between -2.49 and 0 for $800 \mathrm{MHz}$ frequency band, value defined by $\mathrm{K}$ factor propagation model, from which the algorithm below is derived:

$$
\begin{aligned}
& \text { For } \mathrm{j}=4: \mathrm{Nc} \text { do } \\
& \qquad \mathrm{K}_{3}^{\mathrm{j}}=-2.49+2.49 * \text { rand }(1)
\end{aligned}
$$

End for

The overall starting family generation algorithm is therefore with $\mathrm{F}(\mathrm{i}, \mathrm{j})=\mathrm{K}_{\mathrm{i}}^{\mathrm{j}}$; and $\mathrm{F}(\mathrm{i})=K^{i}=\left[K_{1}^{i} K_{2}^{i} K_{3}^{i} K_{4}^{i} K_{5}^{i} K_{6}^{i}\right]$



\section{End for}

End

The appearance order of each parameter above is very important because some parameters are deducted from others.

4.2.1.3 Evaluation functions of each particle. Here, we have to minimize the Euclidean distance between the measured values of the propagation loss and those predicted by the propagation model. Let $L=\left\{L_{j}\right\}_{j=1: N}$ the set of measured values; where $\mathrm{N}$ represents the total number of measurement points of $\mathrm{L} . \mathrm{K}^{\mathrm{j}}$ is a possible solution vector to our optimization problem and $\mathrm{M}_{\mathrm{i}}$ the column vector defined by Eq.(15). The evaluation function [14] of the particles $\mathrm{K}^{\mathrm{j}}$ will be:

$$
\mathrm{f}_{\text {cout }}=\min \left\{\frac{1}{\mathrm{~N}} \sum_{\mathrm{i}=1}^{\mathrm{N}}\left(\mathrm{L}_{\mathrm{i}}-\left(\mathrm{K}^{\mathrm{j}} * \mathrm{M}_{\mathrm{i}}\right)\right)^{2}\right\}
$$

This is for every particle $\mathrm{K}^{\mathrm{j}}$ for $\mathrm{j}=1$ : Nc inside the swarm at any moment. Let remind that $\mathrm{Nc}$ is the number of particles in the swarm. 


\subsubsection{Final algorithm}

Let:

- Kpbesti the best position a particle has achieved (local best position)

- Kvbesti the best position in the swarm (global best position inside the swarm)

- $\quad$ pbesti the best fitness a particle has achieved during the migration (local best fitness of a particle).

- Bestfit, the global best fitness achieved inside the swarm at a position (global best fitness inside the swarm).

In the following algorithm, the symbol "\%" will mean "comment"

Algorithm 2

1 Generation of the swarm's and initial position according to Algorithm 1

2 Evaluation of the fitness of each particle

3 Classification of fitness in descending order

4 Identification of the best particle of the swarm:

Kvbesti and Bestfit its best fitness

$5 \quad$ Storage of Kvbesti and vbesti

6 Parameters initialization

Nit=20; \% After testing 20 displacements are enough iteration $=1$;

$\mathrm{L} ; \quad \% \mathrm{~L}$ is a vector that contains measured loss.

$\mathrm{c} 1=2 ; \mathrm{c} 2=2$

$\mathrm{r} 1=$ rand $(1) ; \mathrm{r} 2=$ rand $(1)$

$\mathrm{p} 1=\mathrm{r} 1 * \mathrm{c} 1 ;$

$\mathrm{p} 2=\mathrm{r} 2 * \mathrm{c} 2$

$\mathrm{p}=\mathrm{p} 1+\mathrm{p} 2$;

$\mathbf{k s}=\mathbf{1 - 1} / \mathbf{p}+\mathbf{0 . 5} * \mathbf{s q r t}(\mathbf{a b s}(\mathbf{p} * \mathbf{p}-\mathbf{4} * \mathbf{p})) ; \quad \%$ sqrt $=$ square root

\section{Matrice $=\operatorname{zeros}(\mathbf{N i t}, 6)$;}

$\%$ Nit*6 matrix containing zeros, it will contain the best fitness at a step.

Matrice(1,:)=Kvbesti; \% We store Kvbesti in the first row

Fit_evolution=zeros $(1$, Nit $)$;

Fit_evolution $(1)=$ Bestfit;

$K=z e r o s(1,6)$;

$\%$ Algorithm Implementation itself.

for iteration=2: Nit

$\%$ Particles fitness evaluation

for $\mathrm{i}=1: \mathrm{Nc}$

$$
\begin{aligned}
& \mathbf{K}=\mathbf{F}(\mathbf{i},:) ; \\
& e=\left(L-(K * M)^{\prime}\right)^{\prime} ;
\end{aligned}
$$

Fitness $(\mathbf{i})=1 / \mathbf{m}^{*}\left(\mathrm{e}^{*} \mathrm{e}^{\prime}\right)$;

end

$\%$ searching of a local minimal of each particle

for $\mathrm{i}=1$ : Nc

if $\quad$ Fitness(i) $<$ pbest(i)

$\operatorname{pbest}(\mathbf{i})=$ Fitness $(i)$;

Fpbest(i,:)=F(i,:);

end

$\%$ searching of a global minimal in the swarm at a

position

\section{if Fitness(i) $<$ Bestfit}

Bestfit=Fitness(i);

Kvbesti=F(i,:);

end

end

$\%$ implementation of the displacement of each particle

for $\mathrm{i}=1: \mathrm{Nc}$

$$
\begin{aligned}
& \text { p1=2* } \operatorname{rand}(1) ; p 2=2 * \operatorname{rand}(1) ; \\
& \mathrm{p}=\mathrm{p} 1+\mathrm{p} 2 \text {; } \\
& \text { ks }=1-1 / p+0.5 * \operatorname{sqrt}(\operatorname{abs}(p * p-4 * p)) \text {; }
\end{aligned}
$$

$\%$ velocity calculation

$V(i,:)=k s *(\operatorname{Vg}(i,:)+p 1 *(F p b e s t(i,:)$ -

$\mathbf{F}(\mathbf{i},:))+\mathbf{p} 2 *(K v b e s t i-\mathbf{F}(\mathbf{i}, \mathbf{:})))$;

$F(i,:)=F(i,:)+V(i,:) ; \%$ New particle position

end

$\mathbf{V g}=\mathbf{V} ; \quad \%$ Velocity updated for next iteration

\%saving of the best particle and its fitness in every iteration

Matrice(iteration,:)=Kvbesti;

Fit_evolution(iteration)=Bestfit;

\section{End}

After the implementation of this algorithm with get the results present in the following section.

\section{RESULT AND COMMENTS}

Having implemented the PSO as described above on the radio measurement data obtained in Yaoundé. By setting the parameters as follows:

$\mathrm{Nc}=60 ; \mathrm{Nit}=20 ; \mathrm{c} 1=2 ; \mathrm{c} 2=2$, the obtained results are presented below. Nit is the number of swarm displacements, $\mathrm{Nc}$ the number of particles.

The model will be seen as accurate if the RMSE between the values of prediction and measured is less than $8 \mathrm{~dB}$; (RMSE < $8 \mathrm{~dB})$. [15]

\subsection{Results by area}

After the implementation of the PSO as described above, we obtain the representatives curves below, the actual measurements are in blue, Okumura Hata model in green, and the free space propagation model in yellow. The new model obtained via PSO in red and that obtained by implementing 
the linear regression in black. Note that linear regression here refers to least square method implementation.

The results and curves obtained using linear regression (least mean square) is presented because in the scientific literature related to propagation model tuning most authors used it or one of its variants as optimization procedure, this will help us to have a better appreciation of the new approach presented.

\subsubsection{Area A1 and A2: Yaoundé centre town and Bastos (Embassy area).}

Fig. 4 and Fig. 5 below represent the actual measurements data and the predicted ones using various propagation models in the centre town of Yaoundé and Bastos respectively.

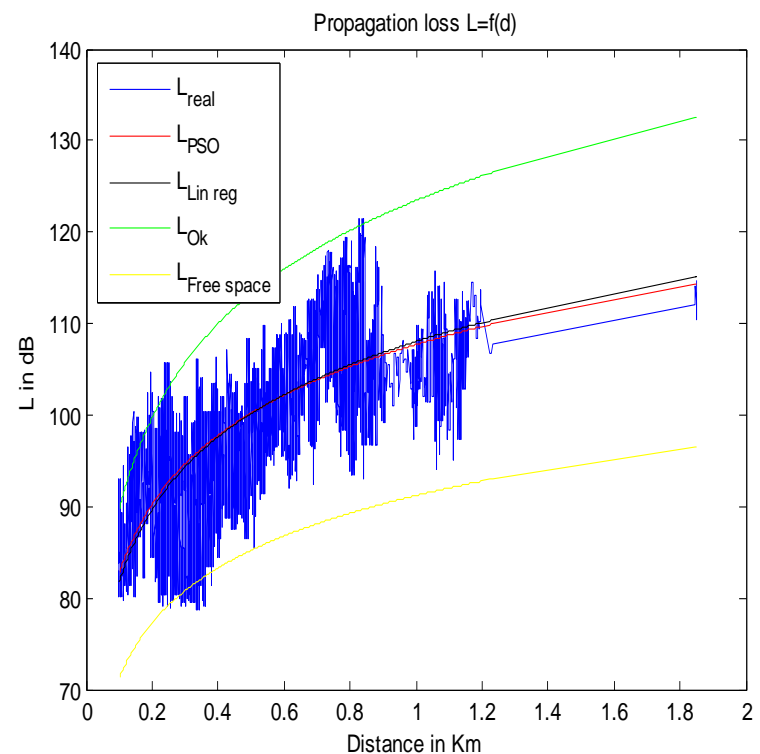

Figure 4: Actual data VS prediction using PSO in area A1

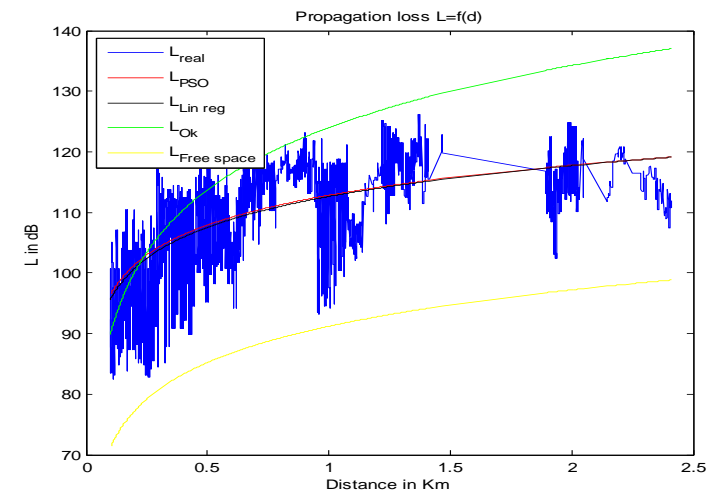

Figure 5: Actual data VS prediction using PSO in area A2

The table below gives the results using PSO and linear regression for area $\mathrm{A} 1$ and $\mathrm{A} 2$.

Table 7. $\mathrm{K}$ values from Centre town and Bastos area.

\begin{tabular}{|c|l|c|c|c|c|c|c|}
\hline Area & Algorithm & K1 & K2 & K3 & K4 & K5 & K6 \\
\hline A1 & PSO & $\mathbf{1 2 1 . 7 7}$ & $\mathbf{3 5 . 9 8}$ & $\mathbf{- 2 . 4 9}$ & $\mathbf{0}$ & $\mathbf{- 6 . 1 8}$ & $\mathbf{- 6 . 5 5}$ \\
\cline { 2 - 8 } & Lin reg & 134.88 & 37.29 & -2.49 & 0 & -13.82 & -6.55 \\
\hline A2 & PSO & $\mathbf{1 1 3 . 6 0}$ & $\mathbf{2 7 . 1 8}$ & $\mathbf{- 2 . 4 9}$ & $\mathbf{0}$ & $\mathbf{1 . 8 1}$ & $\mathbf{- 6 . 5 5}$ \\
\cline { 2 - 8 } & Lin reg & 138.93 & 27.71 & -2.49 & 0 & -13.82 & -6.55 \\
\hline
\end{tabular}

Note that for the model got from PSO (see Table 8) we have a RMSE $<8 \mathrm{~dB}$ which confirms the reliability of the result and model quality which in this environment is better than the one of Okumura Hata. The value of the RMSE obtained by PSO is almost the same with linear regression one.

Table 8: RMSE values in Centre town and Bastos.

\begin{tabular}{|c|l|c|}
\hline \multirow{2}{*}{ A1 } & Propagation models & $\begin{array}{c}\text { Root Mean square } \\
\text { error value for each } \\
\text { result }\end{array}$ \\
\cline { 2 - 3 } & $\begin{array}{l}\text { New model based on PSO } \\
\text { Lin reg }\end{array}$ & $\mathbf{6 . 7 2 2 7}$ \\
\cline { 2 - 3 } & Okumura Hata model & 6.7137 \\
\hline A2 & \begin{tabular}{l} 
New model based on PSO \\
\cline { 2 - 3 }
\end{tabular} & $\begin{array}{l}\text { Optimized model based on } \\
\text { Lin reg }\end{array}$ \\
\cline { 2 - 3 } & Okumura Hata model & 6.10 \\
\hline
\end{tabular}

5.1.2 Area B1 and B2: Hotel du plateau-Essos and Biyem Assi.

For Hotel du plateau-Essos and Biyem Assi, the following figures represent measurements data and predicted ones, Fig.6 is related to B1 and Fig.7 to B2.

Let notify that all these areas are urban ones; so we can compare the RMSE obtained with the one of Okumura Hata to show that the new model is accurate and precised.

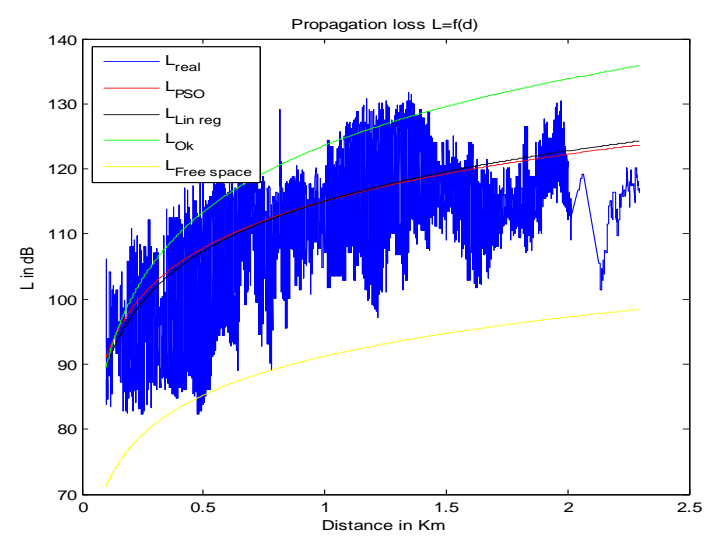

Figure 6: Actual data VS prediction using PSO in area B1



Figure 7: Actual data VS prediction using PSO in area B2 
The table below gives the results using PSO and linear regression for area $\mathrm{B} 1$ and $\mathrm{B} 2$.

Table 12. $\mathrm{K}$ values from area $\mathrm{B} 1$ and $\mathrm{B2}$.

\begin{tabular}{|c|l|c|c|c|c|c|c|}
\hline Area & Algorithm & K1 & K2 & K3 & K4 & K5 & K6 \\
\hline B1 & PSO & $\mathbf{1 2 6 . 9 0}$ & $\mathbf{3 4 . 8 7}$ & $\mathbf{- 2 . 4 9}$ & $\mathbf{0}$ & $\mathbf{- 4 . 9 0}$ & $\mathbf{- 6 . 5 5}$ \\
\cline { 2 - 8 } & Lin reg & 141.75 & 36.53 & -2.49 & 0 & -13.82 & -6.55 \\
\hline \multirow{2}{*}{ B2 } & PSO & $\mathbf{1 1 3 . 8 7}$ & $\mathbf{3 1 . 5 2}$ & $\mathbf{- 2 . 4 9}$ & $\mathbf{0}$ & $\mathbf{- 1 . 7 3}$ & $\mathbf{- 6 . 5 5}$ \\
\cline { 2 - 8 } & Lin reg & 131.90 & 23.16 & -2.49 & 0 & -13.82 & -6.55 \\
\hline
\end{tabular}

Table 13. RMSE values in area B1 and B2.

\begin{tabular}{|c|l|c|}
\hline \multirow{2}{*}{ B1 } & Propagation models & $\begin{array}{c}\text { Root Mean square } \\
\text { error value for each } \\
\text { result }\end{array}$ \\
\cline { 2 - 3 } & $\begin{array}{l}\text { Optimized model based on } \\
\text { Lin reg }\end{array}$ & $\mathbf{7 . 4 0}$ \\
\cline { 2 - 3 } & Okumura Hata model & 7.39 \\
\hline B2 & New model based on PSO & 11.60 \\
\cline { 2 - 3 } & $\begin{array}{l}\text { Optimized model based on } \\
\text { Lin reg }\end{array}$ & 5.83 \\
\cline { 2 - 3 } & Okumura Hata model & 12,36 \\
\hline
\end{tabular}

For area $\mathrm{B} 1$ and $\mathrm{B} 2$, it is found that the RMSE obtained using PSO is also less than $8 \mathrm{~dB}$; this shows the accuracy of PSO algorithm. Even the curves obtained with the implementation of PSO and linear regression are much closed.

\subsection{Comparison between PSO and Linear regression.}

The following tables present a comparison between PSO and linear regression. The target of this is to show the simplicity of PSO and the diversity of solutions it can provide. Linear regression provides a unique solution assuming 4 parameters constant in the existing model.

Table 14: PSO VS linear regression (1)

\begin{tabular}{|c|c|c|c|c|c|}
\hline $\mathrm{N}^{\circ}$ & Method & $\begin{array}{c}\text { Form of the } \\
\text { variable }\end{array}$ & $\begin{array}{c}\text { Variable } \\
\text { name }\end{array}$ & $\begin{array}{c}\text { Set of } \\
\text { variables }\end{array}$ & $\begin{array}{c}\text { Set's } \\
\text { size }\end{array}$ \\
\hline 2 & PSO & $\begin{array}{c}\mathbf{K} \\
(\mathbf{1} * \mathbf{6} \text { size } \\
\text { vector })\end{array}$ & Particle & Swarm & $\mathrm{Nc}$ \\
\hline $\begin{array}{c}\text { Linear } \\
\text { regression }\end{array}$ & $\begin{array}{c}\mathbf{T} \\
\mathbf{( 1 * 2} \text { size } \\
\text { vector })\end{array}$ & T vector & $\begin{array}{c}\text { Single } \\
\text { vector }\end{array}$ & 1 \\
\hline
\end{tabular}

Table 15: PSO VS linear regression (2)

\begin{tabular}{|c|c|c|c|c|}
\hline $\mathrm{N}^{\circ}$ & $\begin{array}{c}\text { Number of } \\
\text { iterations }\end{array}$ & $\begin{array}{c}\text { Fitness } \\
\text { evaluation }\end{array}$ & $\begin{array}{c}\text { Types of } \\
\text { operations on set }\end{array}$ & $\begin{array}{c}\text { Evaluation } \\
\text { method }\end{array}$ \\
\hline
\end{tabular}

\begin{tabular}{|c|c|c|c|c|}
\hline 1 & Nit & $\begin{array}{c}\text { Mean } \\
\text { squared } \\
\text { error }\end{array}$ & $\begin{array}{c}\text { velocity and } \\
\text { displacement }\end{array}$ & $\begin{array}{c}\text { Minimizati } \\
\text { on of MSE }\end{array}$ \\
\hline 2 & 1 & $\begin{array}{c}\text { Mean } \\
\text { squared } \\
\text { error }\end{array}$ & $\begin{array}{c}\text { Linear regression } \\
\text { coefficients } \\
\text { calculation }\end{array}$ & $\begin{array}{c}\text { Minimizati } \\
\text { on of MSE }\end{array}$ \\
\hline
\end{tabular}

Table 16: PSO VS linear regression (3)

\begin{tabular}{|c|c|c|c|c|c|}
\hline$N^{\circ}$ & Method & $\begin{array}{c}\text { Implem } \\
\text { entation } \\
\text { time in } \\
\text { sec }\end{array}$ & $\begin{array}{c}\text { Stopping } \\
\text { criteria }\end{array}$ & $\begin{array}{c}\text { Number of } \\
\text { optimized } \\
\text { parameters }\end{array}$ & $\begin{array}{c}\text { Diversity } \\
\text { of the } \\
\text { solution }\end{array}$ \\
\hline 1 & PSO & 0.3570 & $\begin{array}{c}\text { Based on } \\
\text { maximu } \\
\mathrm{m} \\
\text { number } \\
\text { of } \\
\text { iterations } \\
\text { or RMSE } \\
\text { threshold }\end{array}$ & $2 \leq \mathrm{N} \leq 6$ & Yes \\
\hline 2 & $\begin{array}{c}\text { Linear } \\
\text { regressi } \\
\text { on }\end{array}$ & 0.1544 & None & 2 & No \\
\hline
\end{tabular}

From these tables, it can be seen that PSO takes more time to output a good solution but with PSO we can optimize not only 2 parameters like linear regression but up to 6 . This means that we have more diversity in terms of solution quality from PSO. PSO output a set of good solutions; the best one is retained while linear regression can only output one solution.

\subsection{Summary of results}

In all the area A1, A2, B1, B2, above, the RMSE obtained through the new model made up using PSO algorithm is less than $8 \mathrm{~dB}$ and better than the one calculate using Okumura Hata model. The solution for every zone is the best particle in the swarm at the final position reached after Nit displacements. For the whole town of Yaoundé, we can deduce an average particle (average value of best particle retained by area) which will represent the optimized propagation model for the town of Yaoundé. The final result and the corresponding formula are given below.

Table 17. Final particle retained as new propagation model

\begin{tabular}{|l|c|c|c|c|c|c|}
\hline $\begin{array}{l}\text { Final } \\
\text { solution }\end{array}$ & K1 & K2 & K3 & K4 & K5 & K6 \\
\hline $\begin{array}{l}\text { PSO } \\
\text { algorithm }\end{array}$ & 119.03 & 32.38 & -2.49 & 0 & -2.75 & -6.55 \\
\hline
\end{tabular}

The corresponding formula for this table is presents by Eq.(21)

$L=119.03+32.38 \log (d)-2.49 * h_{m}-2.75 *$
$\log \left(H_{\text {eff }}\right)-6.55 * \log \left(H_{\text {eff }}\right) * \log (d)$

This final formula can be seen as the propagation model adapted to the environment of Yaoundé and apply for future LTE deployment when the government will enable the use of 4G license. 


\section{CONCLUSION}

This paper presents a new method for the optimization of propagation model relatively to a given environment.

This research is focused not in a specific propagation model like Okumura Hata or Walfisch-Ikegami, but in the general form that a propagation model could have in a specific frequency: the $\mathrm{K}$ factor model. The advantage of doing this is that almost all existing statistical propagation models on a specific frequency could be written in the form of Eq.(2) or Eq.(13). Then we can model our swarm as a set of particles in the form of Eq.(14) and fully design the algorithm. We also explained how to generate the initial swarm. Finally a complete implementation algorithm was proposed and comparative tables between PSO and linear regression to show the diversity of result based on PSO.

The method like linear regression can optimize only 2 parameters, the others are supposed constant while through PSO algorithm all the parameters could be optimized, the solution output has more diversity that the one of linear regression.

The method described here could very well be used to design or calibrate propagation models. The advantages of this approach is that, the PSO algorithm doesn't provide unique solution to the problem, but a set of good solutions according to the stopping criteria (based on the number of displacements or the acceptable RMSE), amongst these solutions, the best one (with minimum value of RMSE) in the final swarm position is selected as the final.

Measurements made in the city of Yaoundé as application gave us very good results with an RMSE less than $8 \mathrm{~dB}$ in all the selected areas in the city. Compared to Okumura Hata's RMSE obtained, the new model gives a better and accurate result. The results obtained are very similar to those obtained by the method of linear regression used by most authors around the world as calibration procedure.

\section{REFERENCES}

[1] Deussom E. and Tonye E. «New Approach for Determination of Propagation Model Adapted To an Environment Based On Genetic Algorithms: Application to the City Of Yaoundé, Cameroon», IOSR Journal of Electrical and Electronics Engineering, Volume 10, pages 48-49, 2015

[2] R. Mardeni and K. F. Kwan «Optimization of Hata prediction model in suburban area in Malaysia» Progress In Electromagnetics Research C, Vol. 13, pages 91-106, 2010 .

[3] Chhaya Dalela, and all «tuning of Cost231 Hata modele for radio wave propagation prediction », Academy \& Industry Research Collaboration Center, May 2012.
[4] Medeisis and Kajackas «The tuned Okumura Hata model in urban and rural zones at Lituania at 160, 450, 900 and $1800 \mathrm{MHz}$ bands », Vehicular Technology Conference Proceedings, VTC 2000-Spring Tokyo. IEEE 51st Volume 3 Pages 1815 - 1818, 2000.

[5] Deussom E. and Tonye E. [5] worked on «Optimization of Okumura Hata Model in $800 \mathrm{MHz}$ based on Newton Second Order algorithm. Case of Yaoundé, Cameroon", IOSR Journal of Electrical and Electronics Engineering, Volume 10, issue2 Ver I, pages 16-24, 2015.

[6] MingjingYang; and al «A Linear Least Square Method of Propagation Model Tuning for 3G Radio Network Planning », Natural Computation, 2008. ICNC '08. Fourth International Conference on Vol. 5, pages 150 154, 2008.

[7] Chen, Y.H. and Hsieh, K.L «A Dual Least-Square Approach of Tuning Optimal Propagation Model for existing 3G Radio Network», Vehicular Technology Conference, 2006. VTC 2006-Spring. IEEE 63rd Vol. 6, pages $2942-2946,2006$.

[8] Allam Mousa, Yousef Dama and Al «Optimizing Outdoor Propagation Model based on Measurements for Multiple RF Cell ». International Journal of Computer Applications (0975 - 8887) Volume 60- No.5, December 2012

[9] HUAWEI Technologies, CW Test and Propagation Model Tuning Report, page 7, 20 Mars 2014.

[10] HUAWEI Technologies, BTS3606CE\&BTS3606AC and 3900 Series CDMA Product Documentation, pages 138 139.

[11] Standard Propagation Model Calibration guide, Avril 2004, page 23.

[12] Riccardo Poli, James Kennedy, and Tim Blackwell. Particle swarm optimization. Swarm Intelligence, pages: 33-57, 2007.

[13] Russell C. Eberhart, Yuhui Shi, and James Kennedy. Swarm Intelligence. The Morgan Kaufmann Series in Artificial Intelligence. Morgan Kaufmann, San Francisco, CA, USA, 2001.

[14] Maurice Clerc and James Kennedy The particle swarm - explosion, stability, and convergence in a multidimensional complex space. IEEE Trans. Evolutionary Computation, 6(1):58-73, 2002.

[15] HUAWEI Technologies, Radio Transmission Theory, page 24, 11 Nov 2005. 